\title{
New Methods of Burden Distribution Control in
}

\section{Bell-armour Charging*}

\author{
By Tomio HARU,,* Mitsuo SAINO,** Motozo YASUNO,** Kazuo OKUMURA,** \\ Ken-ichi KANEKO,** Yukio KONISHI*** and Toshiro SAWADA**
}

\section{Synopsis}

Under the present situation which is forced to reduce the productivity of the all coke operation, it is important to establish such a distribution adjusting technique as to maintain an adequate peripheral gas flow and a sharp central gas flow simultaneously. The gas distribution in a furnace equipped with a bell-armour in comparison with that of the bell-less top has a tendency to flatten owing to the difference in size segregation behaviour in the radial direction, thus posing a problem in micro-control of the burden distribution.

The authors have recently developed a new technique of controlling the burden distribution by the movable armour and applied it to Chiba No. 5 Blast Furnace. The technique is aimed at improving the layer thickness and promoting the particle size segregation in the radial direction, slowing down the raw material discharging rate from the bell by controlling the bell stroke and speed.

By the application of this technique, it has made possible to strengthen both the peripheral gas flow and central gas flow simultaneously, and thus has greatly contributed to stabilizing the furnace condition and extention of the permitted limit for operation under the recent circumstances of reduced production.

\section{Introduction}

The burden distribution control in the blast furnace operation has remarkably progressed. By the introduction of movable armour (abbreviated to MA) and bell-less charging equipment and the development of various in-furnace sensors, excellent operation results ${ }^{1-3)}$ of blast furnaces have been achieved. In view of the recent trend toward the reduction of production level and the all-coke operation, the supression of scaffold generation and the control of peripheral gas flow to decrease $\mathrm{Si}$ content in pig iron have become important.

In the bell-armour charging equipment which is used for about $80 \%$ of domestic blast furnaces being operated, the technique of stabilizing the blast furnace for a long period of time is not sufficiently established yet, because burden distribution control is not conducted thoroughly as compared with that of bell-less top.

In Chiba Works having both types of blast furnaces, an attempt to establish the technique of controlling the burden distribution has made by using bell-armour type Chiba No. 5 Blast Furnace (inner volume: 2584 $\mathrm{m}^{3}$ ), after its blowing in, by referring to the operation technique of Chiba No. 6 Blast Fnrnace (inner volume: $4500 \mathrm{~m}^{3}$ ) of bell-less type.

As a result, the burden distribution control in bellarmour blast furnace on the same level as that of bellless type has been achieved by the large bell stroke and speed control technique. This report explains the process of the development and the results obtained by the application of this technique.

\section{Problems for Distribution Control by Bell- armour Charging Method}

\section{Burden Distribution Adjustment by Bell-armour}

Figure 1 shows a schematic diagram of the furnace top equipment of Chiba No. 5 Blast Furnace. It is a 3-bell type medium-size blast furnace with MA of Kawasaki ${ }^{\dagger}$ type prevents dust sticking by making

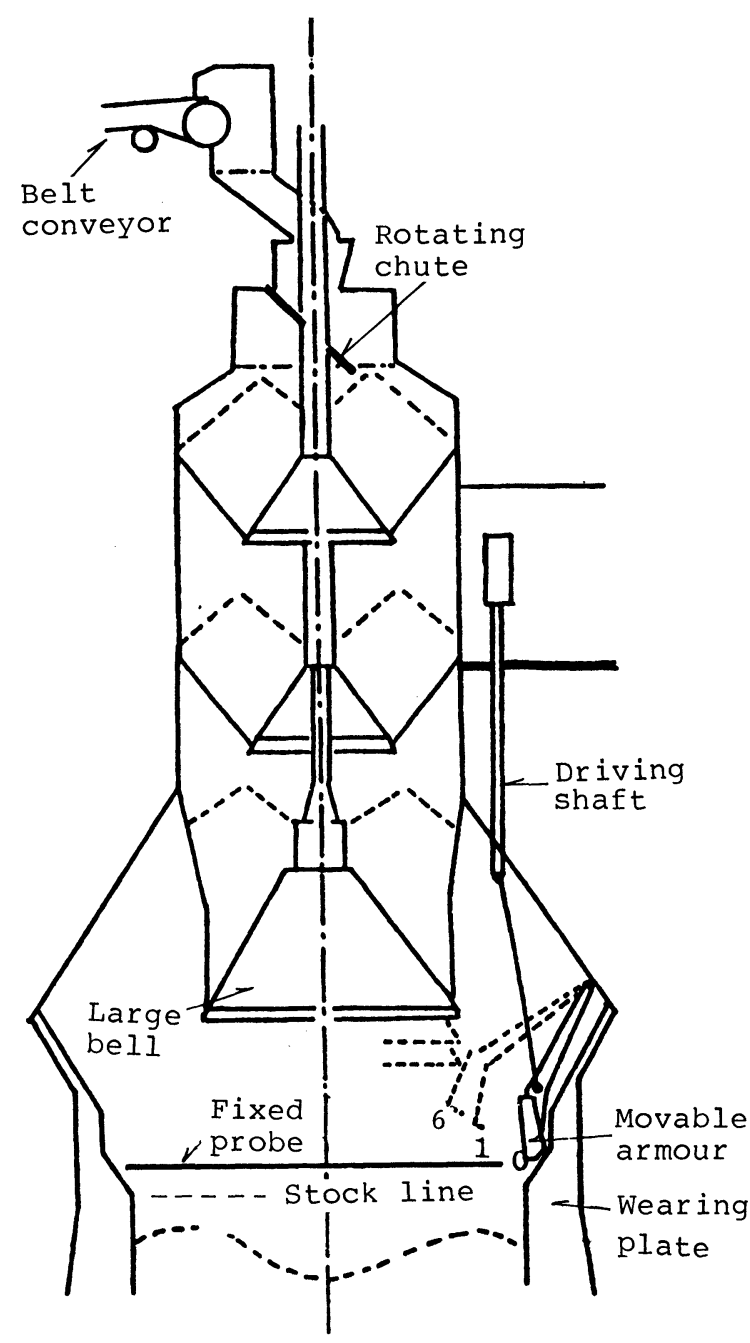

Fig. 1. Scheme of charging equipment of No. 5 Blast Furnace.

* Presented to the 105th ISIJ Meeting, April 1983, S58, at The University of Tokyo in Tokyo. Manuscript received September 8, 1983. (C) 1984 ISIJ

** Chiba Works, Kawasaki Steel Corporation, Kawasaki-cho, Chiba 260.

*** Research Laboratories, Kawasaki Steel Corporation, Kawasaki-cho, Chiba 260.

$\dagger \quad$ Abbreviation of Kawasaki Steel Corporation. 
the driving shaft vertical, and can make significant distribution changes by fine vertical adjustment of the driving shaft. The armour position has been set at 1 to 6 points toward the furnace center at intervals of $54 \mathrm{~mm}$ starting from the position $460 \mathrm{~mm}$ apart from the furnace wall. Charging is made by the "2-batch 1-charge" method.

The distribution condition has been mainly judged by the central gas temperature measured by the fixed probe installed above the burden surface across the furnace direction, and by the stave temperature measured at the steps in the peripheral direction. The stave temperature index, ${ }^{4}$, which is the sum of scores corresponding to readings of thermometers installed in staves, is an index to show the activation condition of the periphery and indicates the intensity of peripheral gas flow.

Figure 2 shows an example that the temperature of hot metal decreases periodically by lowering the central gas temperature of the fixed probe. Also the slip tends to increase, when the stave index lowers. These facts suggest that under the condition of extensively reduced production of about $1.5 \mathrm{t} / \mathrm{m}^{3} \cdot d$ in all coke operation, it is necessary to prevent ${ }^{5)}$ the irregular burden descent due to excess peripheral gas flow and secure $^{6,7)}$ the central gas flow needed for good permeability and discharge of circulating zinc.

On the basis of these findings, the burden distribution has been adjusted by changing the MA position so that it will satisfy both of the stave temperature index and the central temperature of fixed probe.
Figure 3(a) shows the MA position transition at Chiba No. 5 Blast Furnace and the changes in $\Delta T_{C L}$ (difference of central gas temperature and intermediate gas temperature) which indicates the strength of central gas flow for each pattern. Figure 3(b) shows the changes in $\Delta T_{W}$ (difference of peripheral gas temperature and intermediate gas temperature) which indicates the intensity of peripheral gas flow. When the MA position during coke charging is pulled back to the periphery and the MA position during ore charging is set inside the furnace to realize the peripheral gas flow, as shown by arrow marks, $\Delta \mathcal{T}_{W}$ will rise (in hatched pattern on the right figure), while conversely $\Delta T_{C L}$ will decrease (in hatched pattern on the left figure).

As is explained above, fine adjustment for the simultaneous accomplishment of the increase in the central gas flow and the maintenance of the peripheral gas flow, both of which are necessary to operational stability, is difficult to achieve simply by changing the MA position.

\section{Burden Distribution Adjustment by Bell-less Charging}

Figure 4 shows the bell-less pattern transition of Chiba No. 6 Blast Furnace. Indices of abscissa and ordinate in this figure represent the average distance of burden charge from the furnace center when the radius of furnace is defined as unity so as to quantify the pattern involving multiple tilting position. ${ }^{8)}$ After blowing-in, the coke pattern has been shifted to the furnace wall side during the excess central gas flow

Fig. 2. Trends of typical operational results.

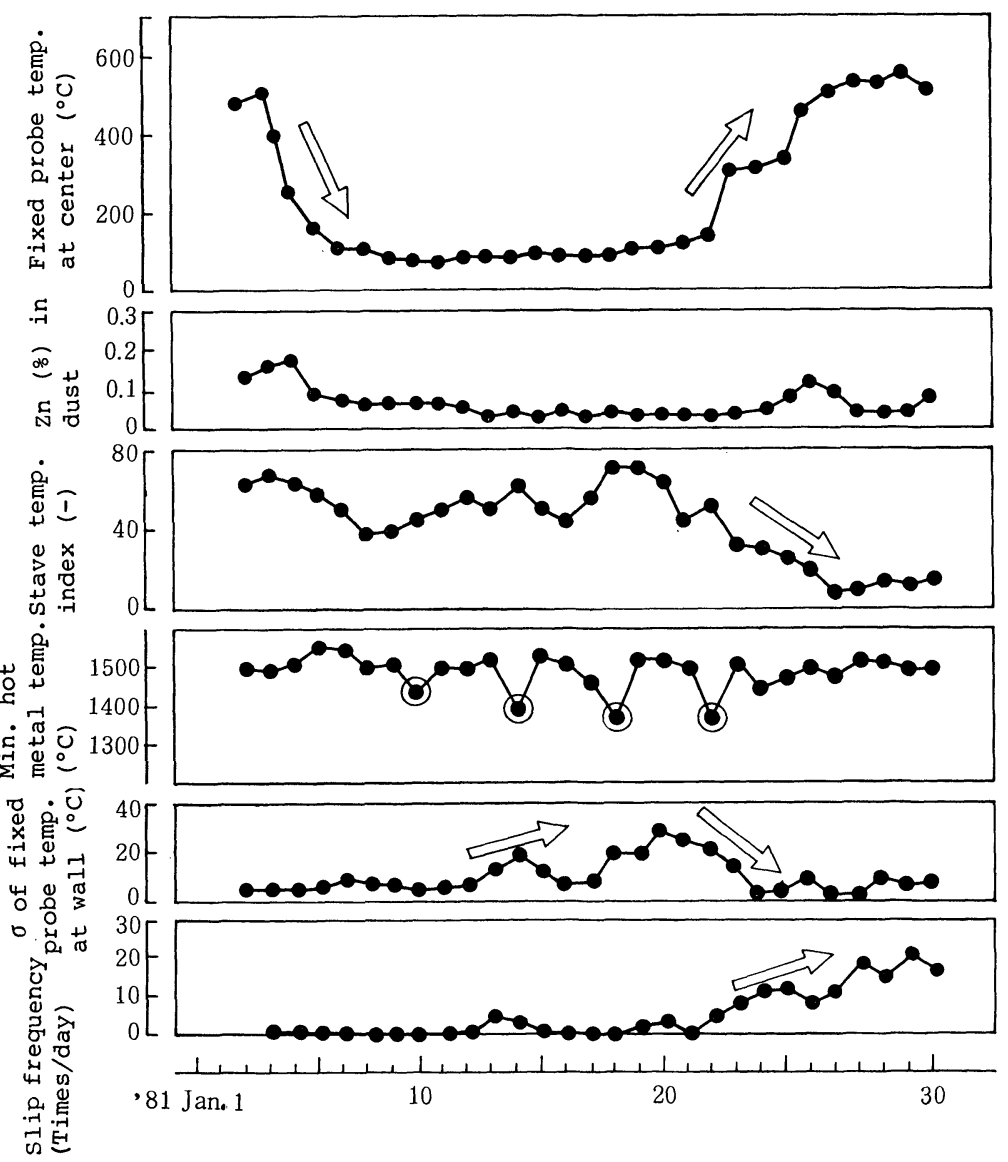




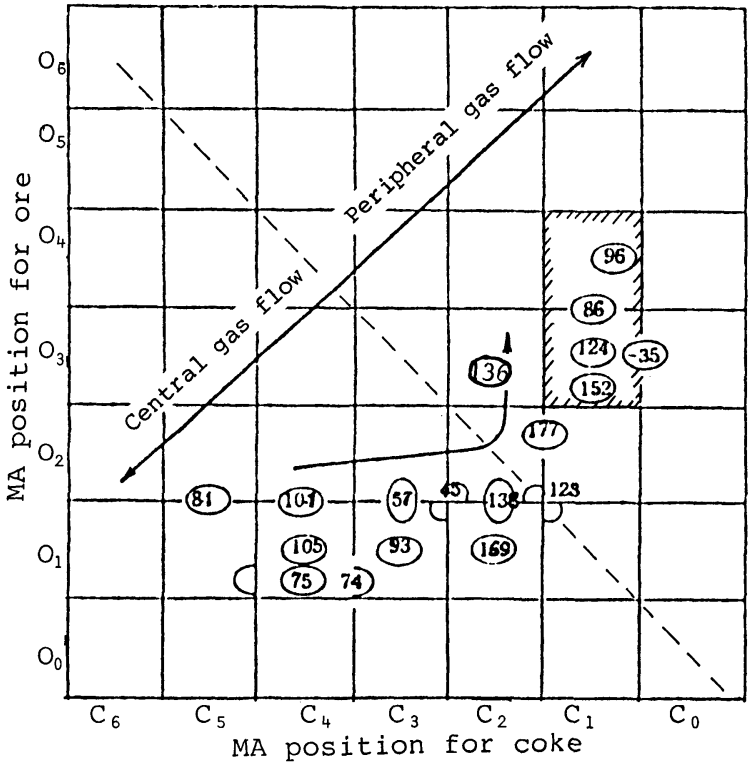

(a) $\Delta T_{C L}$ is shown as figures in circle.

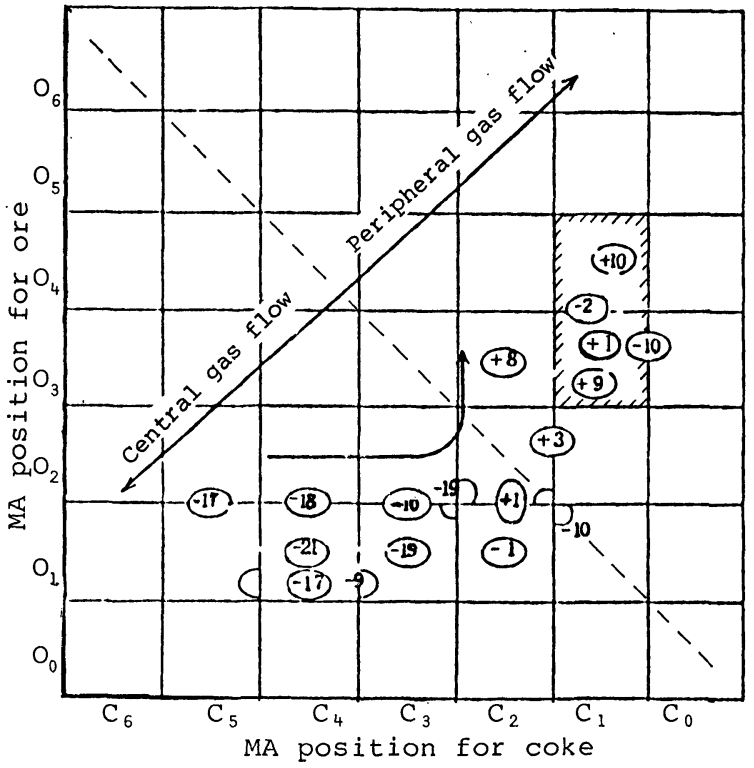

(b) $\Delta T_{W}$ is shown as figures in circle.

Fig. 3. Transition of $\Delta T_{C L}$ (central gas flow) and $\Delta T_{W}$ (peripheral gas flow) at each MA position at Ghiba No. 5 Blast Furnace.

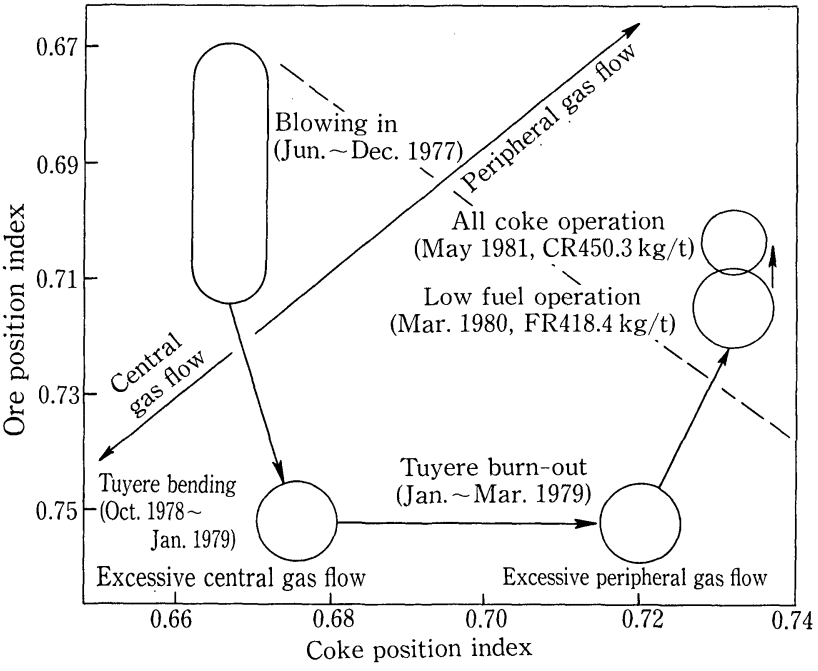

Fig. 4. Transition of bell-less pattern under typical operation at Chiba No. 6 Blast Furnace.

period and excess peripheral gas flow period. In addition to this, the ore pattern has been shifted toward the furnace interior side at low fuel period and all coke period.

Figure 5 shows the examples of the fixed probe temperature distribution in the typical operation periods. Strengthening the gas flow in the periphery and central parts has been simultaneously achieved. In comparison with the pattern positions in Figs. 3 and 4 , it can be understood that the gas flow distribution of bell-armour tends to flatten even if the MA position is conceptually on the same position as that of the comparatively stabilized furnace condition which can be maintained by the bell-less charging. To clarify the difference in both gas distribution and achieve the strengthening of the peripheral gas flow and central gas flow by the bell-armour are judged to be the most important one for the distribution adjust-

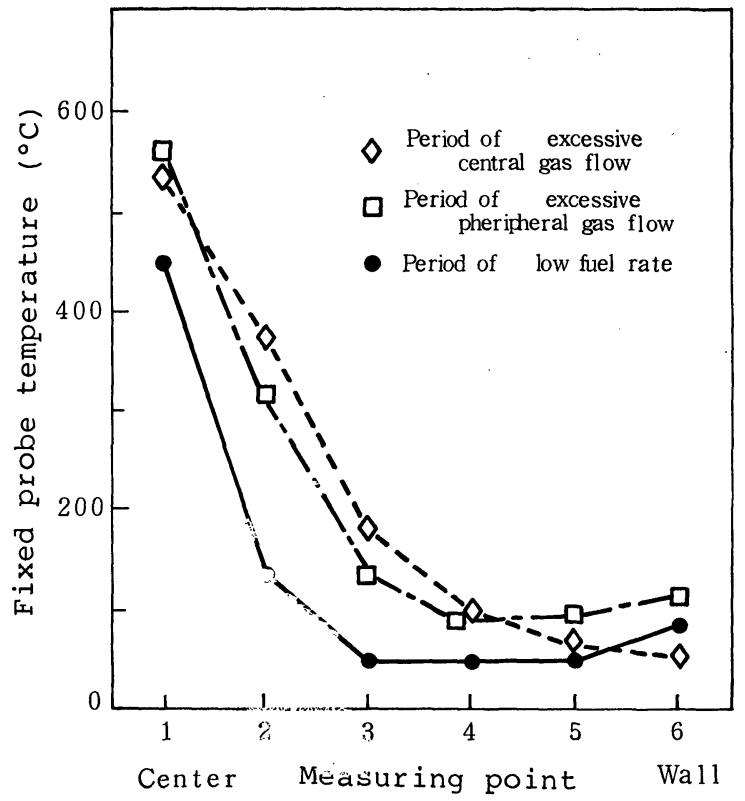

Fig. 5. Comparison of gas temperature distribution at typical operational periods at Chiba No. 6 Blast Furnace.

ing technique.

\section{Comparison of Bell-less and Bell-armour Methods}

Keeping an appropriate gas flow distribution means to control the layer thickness and particle size distribution in the radial direction of furnace. From those view points, the bell-less and MA charging methods are compared.

Figure 6 shows a schematic diagram of discharging phenomena of bell-less and bell-armour types. The differences in the charging conditions of the two types are as follows:

1) Change in particle size of raw materials charged from the furnace top hopper, 
Fig. 6 .

Scheme of discharging phenomena of bell-less type and bell-armour type.

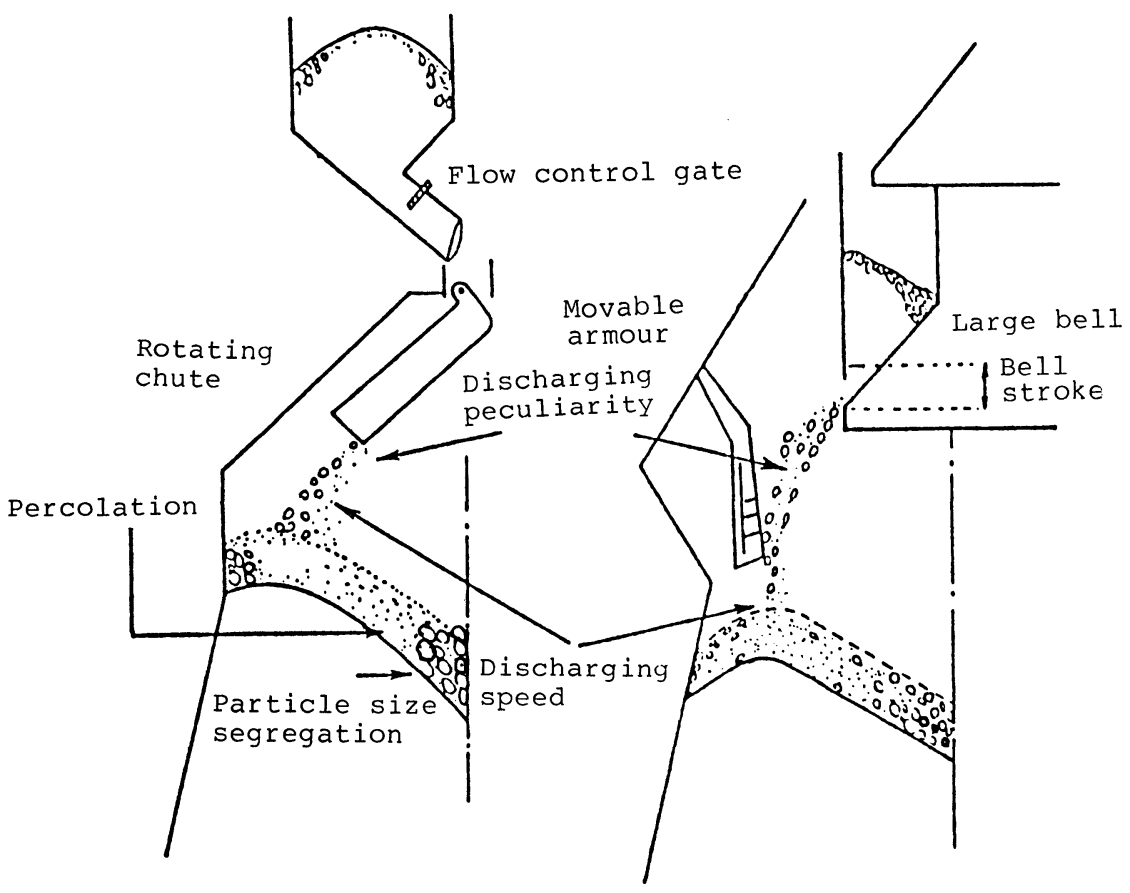

2) Failing trajectory in respect of the burden surface,

3) Number of successive charging of materials, and

4) Rate and time of raw material charging from the hopper.

These factors bring about the difference in the burden profile, particle size segregation, percolation and mixed layer formation. It is well known that the bell blast furnace has a smaller profile angle and less particle size segregation than those of bell-less type. ${ }^{9)}$

As an improving method of the burden distribution for bell-armour blast furnace, the followings are known:

1) Separate material charging, ${ }^{10)}$ and

2) Size-segregated sinter charging. ${ }^{11)}$

The former is aimed at controlling the layer thickness and particle size in the radial direction of furnace by increasing the number of batches or reducing the charging quantity per dump, and the latter is aimed at the same control by charging coarse particles actively to the central part of furnace.

From the findings concerning the bell-less equipment, the authors have paid attention to reduce the charging rate from bell hopper which is considered to be the most effective way to improve the particle size segregation and to lower the ore layer thickness in the central region to prevent flattening of the gas flow distribution.

\section{Development of New Distribution Control Technique by Bell-armour}

\section{Effect of Charging Rate on Particle Size Segregation}

Figure 7 shows a simple model in which raw material particles collide to the burden surface angle $\alpha$ with the charging angle $\gamma$ and charging rate $V$. As an assumption, the vertical component after collision is neglected. The raw material particles slide the slope after colliding the burden slope with a speed

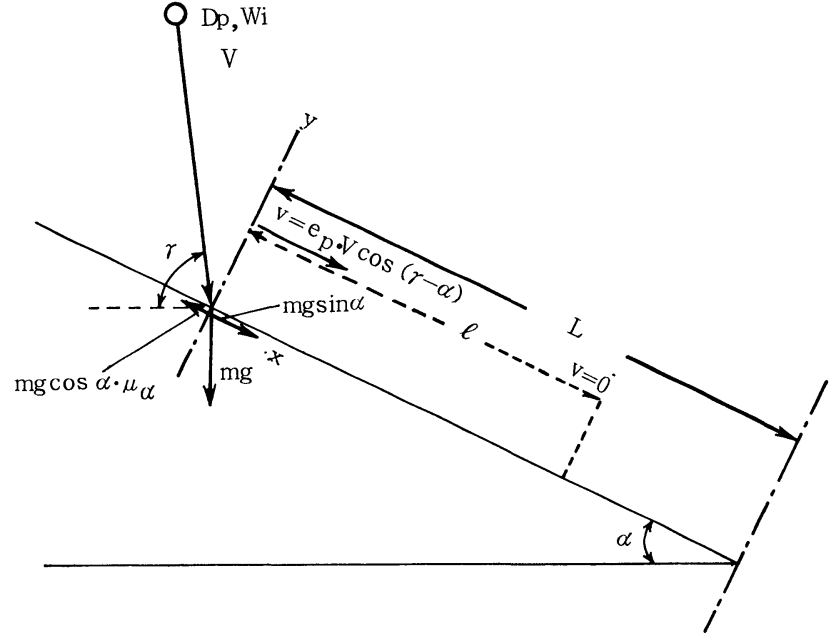

Fig. 7. Simulation model of size segregation.

component $v$ which takes into consideration the repulsion coefficient " $e_{p}$ " in the direction parallel to the slope. Then the raw material particle is assumed to stop at slope length $l$ while being acted on by the friction resistance $\mu_{\alpha}$.

Repulsion index " $e_{p}$ " closely resembles to the index function of the harmonic mean diameter.

$$
e_{p}=1-1 / e^{\left(0.2 D_{p}-0.1\right)}
$$

It is considered that " $e_{p}$ " depends on the harmonic mean diameter according to the calculation which is taken into account the rolling at the time of collision. Friction coefficient accumulated distribution function $F\left(\mu_{\alpha}\right)$ is shown in Fig. 8:

$$
F\left(\mu_{\alpha}\right)=1-e \frac{-\left(\mu_{\alpha}-0.40\right)^{0.75}}{1.3}
$$

This formula indicates that $F\left(\mu_{\alpha}\right)$ closely resembles the Weibull function. 
If the harmonic mean diameter and weight distribution of the charged material and, as the initial condition, charging rate $V$, charging angle $\gamma$ and the burden surface angle $\alpha$ are given, it is possible to calculate the position on the slope of length $L$ and the ratio of particles of certain diameter being accumulated by the following equation of motion:

$$
\begin{gathered}
m \frac{d x^{2}}{d t^{2}}=m g \cdot \sin \alpha-m g \cdot \cos \alpha \cdot \mu_{\alpha} \\
\frac{d x}{d t}=g\left(\sin \alpha-\cos \alpha \cdot \mu_{\alpha}\right) t+e_{p} \cdot v \cos (\gamma-\alpha)
\end{gathered}
$$

Time until stopping:

$$
T=-e_{p} \cdot v \cos (\gamma-\alpha) / g\left(\sin \alpha-\cos \alpha \cdot \mu_{\alpha}\right)
$$

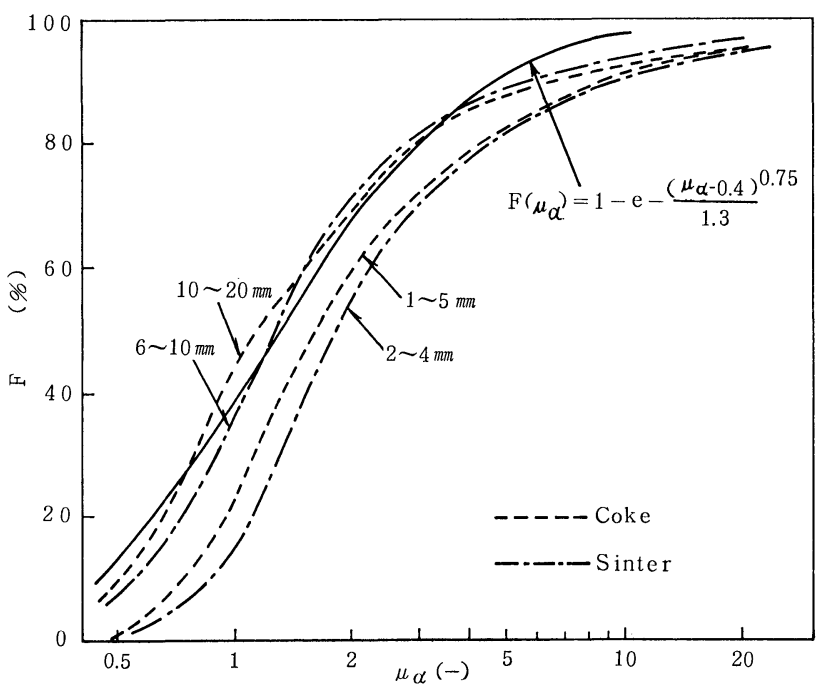

Fig. 8. Frictional coefficient distribution.

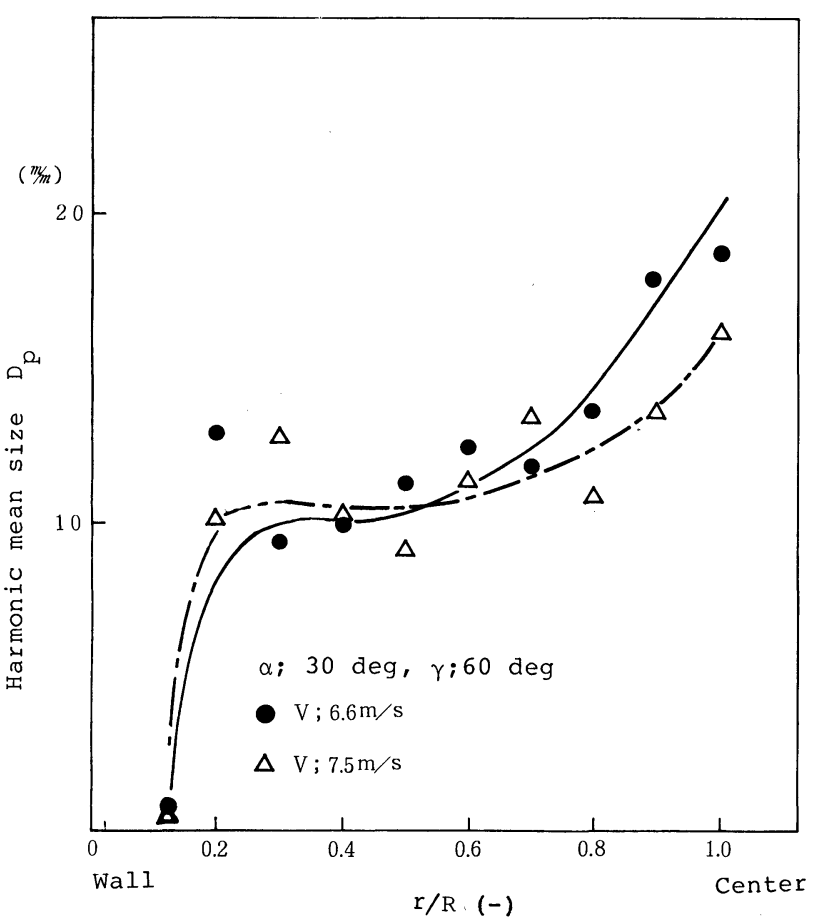

Fig. 9. Results of calculated size segregation.
Distance until stopping:

$$
l=-\frac{1}{2}\left\{e_{p} \cdot v \cos (\gamma-\alpha)\right\}^{2} / g\left(\sin \alpha-\cos \alpha \cdot \mu_{\alpha}\right)
$$

Figure 9 shows the results of calculation for the particle size distribution in the slope length direction when the initial charging rate from large bell is changed. When the discharging rate is slowed, the advancement of the segregation is observed. The result explains the existing findings ${ }^{12}$ ) that the discharging rate is slowed by flow control gate to charge uniformly the raw material in the bell-less blast furnace, and as its charging method features, particle size segregation becomes large by rolling on the slope because of large charging angle which causes the reduction of speed.

\section{Distribution Investigation by Scale Model}

Before introducing the bell stroke and speed control technique, the distribution has been investigated by a scale model. Figure 10 shows the furnace top equipment of a size equivalent to $1 / 15$ of Chiba No. 5 Blast Furnace.

It is a sectional model with a transparent glass on the front. Table 1 shows the particle size distribution of the test sample. After evenly filling the large bell with the raw material and while blowing air at

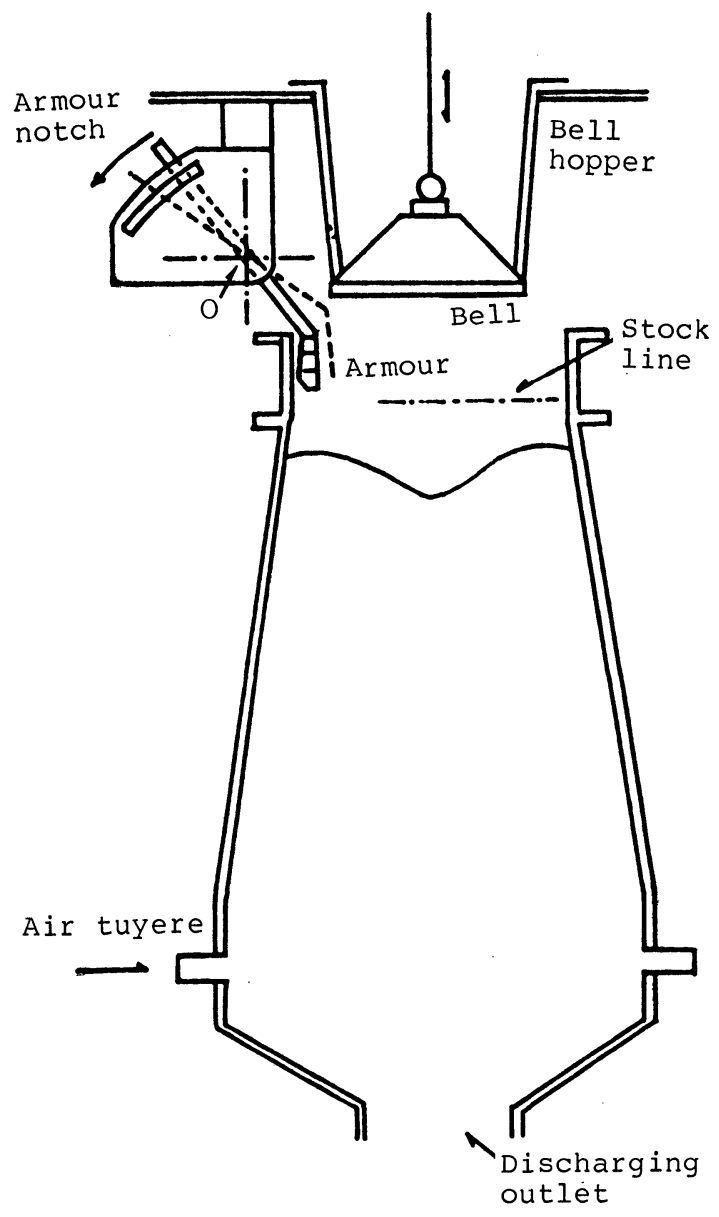

Fig. 10. 1/15 scale model of Chiba No. 5 Blast Furnace. 
Table 1. Comparison of particle size.

\begin{tabular}{|c|c|c|c|c|}
\hline & \multicolumn{2}{|c|}{ No. 5 Blast Furnace } & \multicolumn{2}{|c|}{$1 / 15$ scale segment model } \\
\hline & $\begin{array}{l}\text { Particle size } \\
(\mathrm{mm})\end{array}$ & (wt \%) & $\begin{array}{l}\text { Particle size } \\
(\mathrm{mm})\end{array}$ & (wt \%) \\
\hline \multirow{9}{*}{ Ore } & +50 & 4.7 & $4 \sim 3$ & 4.2 \\
\hline & $50 \sim 35$ & 5.5 & $3 \sim 2$ & 10.1 \\
\hline & $35 \sim 30$ & 4.1 & $2 \sim 1.5$ & 9.1 \\
\hline & $30 \sim 25$ & 5.3 & $1.5 \sim 1.0$ & 17.1 \\
\hline & $25 \sim 20$ & 8.6 & $1.0 \sim 0.6$ & 33.1 \\
\hline & $20 \sim 15$ & 12.3 & $0.6 \sim 0.4$ & 14.4 \\
\hline & $15 \sim 10$ & 25.8 & $0.4 \sim 0.2$ & 12.0 \\
\hline & $10 \sim 5$ & 28.7 & & \\
\hline & $\sim 5$ & 5.0 & & \\
\hline \multirow{5}{*}{ Goke } & +100 & 0.0 & $6 \sim 4$ & 27.5 \\
\hline & $100 \sim 75$ & 6.5 & $4 \sim 3$ & 32.5 \\
\hline & $75 \sim 50$ & 43.2 & $3 \sim 2$ & 40.0 \\
\hline & $50 \sim 25$ & 48.4 & & \\
\hline & $\sim 25$ & 1.9 & & \\
\hline
\end{tabular}

a rate of $1.2 \mathrm{~m}^{3} / \mathrm{min}$ from the lower tuyere, the large bell is caused to descend by the specified bell stroke with the specified bell descending speed. The furnace burden is extracted from the lower discharging outlet after charging and left to descend to the stock line. After repeating the procedure several times, the gas flow rate, layer thickness comparison, particle size distribution, etc., are measured in the radial direction.

Figure 11 (a) shows the layer thickness comparison under $\mathrm{C}_{3} \mathrm{O}_{0}$ and $\mathrm{C}_{0} \mathrm{O}_{3}$ charging; Fig. $11(\mathrm{~b})$ shows the layer thickness comparison when changing the bell speed under the conditions of constant bell stroke; and Fig. 11(c) shows the layer thickness comparison when changing the bell stroke under the constant speed conditions.

In Fig. $11(\mathrm{a}), \mathrm{C}_{0} \mathrm{O}_{3}$ charging lowers not only Lo/Lc at the center as compared with $\mathrm{G}_{3} \mathrm{O}_{0}$ charging. Furthermore, $L o / L c$ peak appears near the central region.

This is considered to be attributable to the effect of ore charging on scraping the coke layer and pushing the scraped coke to the central region of furnace. It is considered that the formation of the mixed layer in the central region strengthen the central gas flow. Further, as shown in Figs. 11(b) and (c), the lowered discharging rate from the bell due to reduction in bell stroke and speed reduces the $L o / L c$ peak value near the central region. The reason is considered to be due to the fact that the flow of ore toward the central region of furnace is prevented by decreasing the charging energy.

Figure 12 shows the particle size segregation in the radial direction when the bell stroke and the bell stroke speed are reduced. Longitudinal axis index $D_{p}^{i} / D_{p_{\text {ave. }}}$ indicates the comparison of harmonic mean diameter at each sampling point with respect to the overall harmonic mean diameter of sample. By reducing the discharging rate from the bell, the increase in the particle diameter in the central region and the peripheral region is observed. ${ }^{13)}$

As a result, it is confirmed that the gas flow rate in the radial direction of furnace increases near the
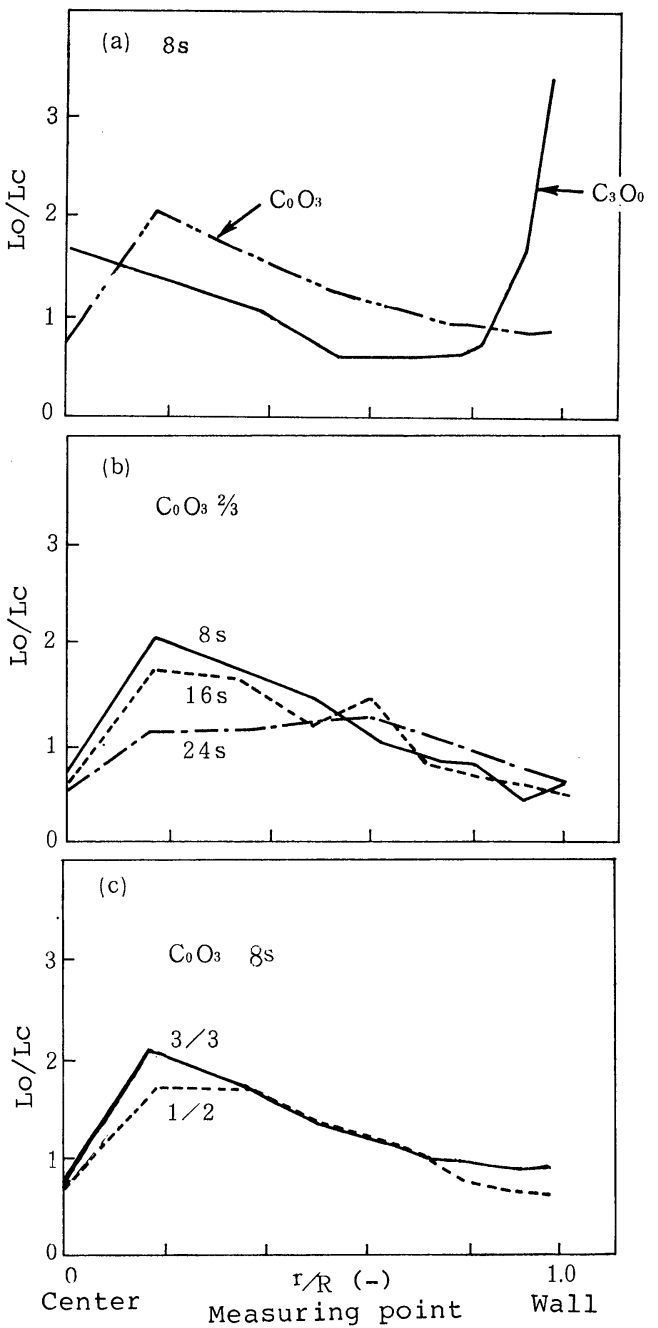

(a) MA position

(b) Bell stroke speed

(c) Bell stroke

Fig. 11. Effect of Ma position, bell stroke speed, and bell stroke on $L o / L c$ in the radial direction.

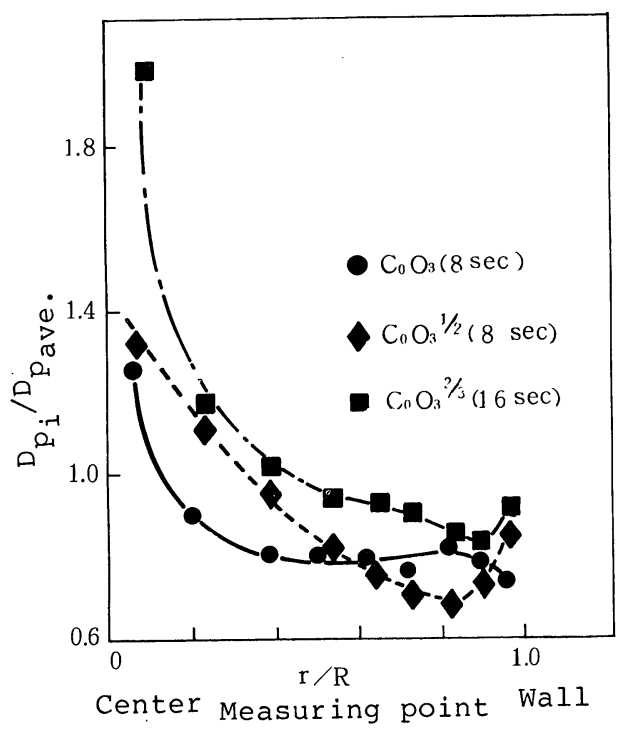

Fig. 12. Effect of bell stroke and bell stroke speed on the harmonic mean diameter in the radial direction. 
central region and the peripheral region by adjusting the bell stroke, as shown in Fig. 13.

\section{Effect of Bell Stroke Control on Falling Trajectory}

Figure 14 shows the control system of large bell stroke and speed at Chiba No. 5 Blast Furnace. The stroke is able to control by the limit switch installed in the bell rod while the speed is able to control by the flow control valve of hydraulic cylinder piping, in the operation.

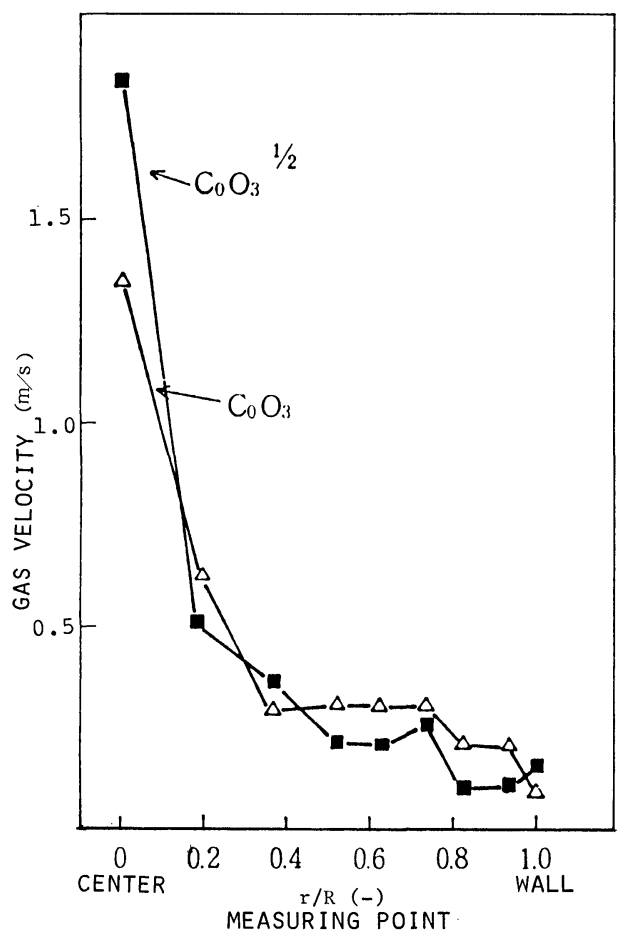

Fig. 13. Effect of gas velocity in radial direction on bell stroke.

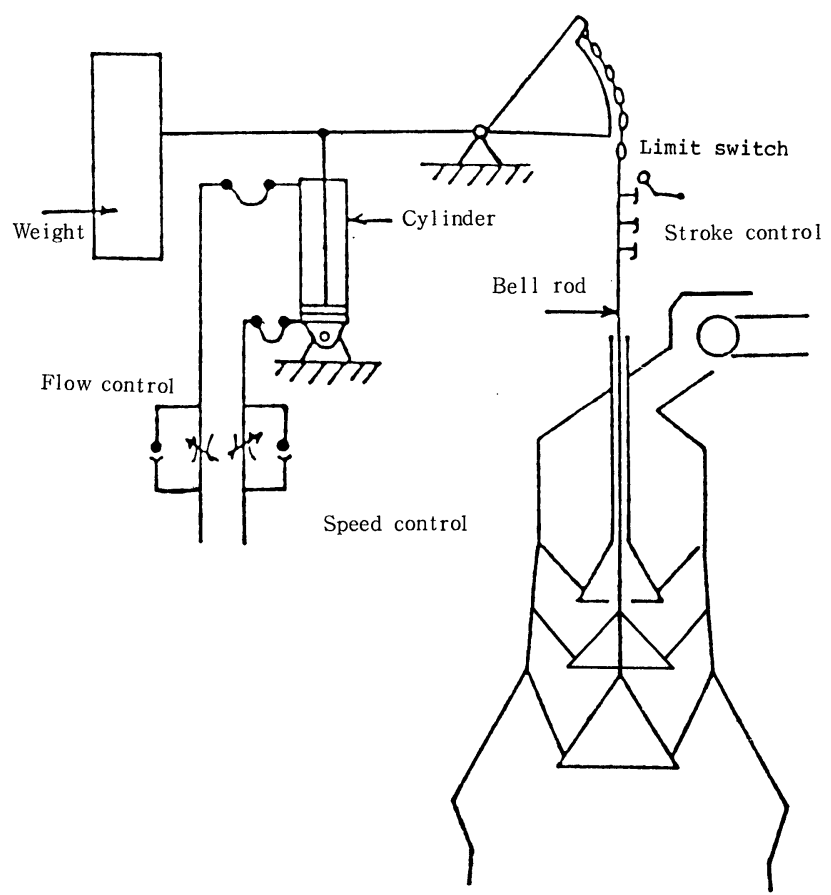

Fig. 14. Control system of bell stroke and bell speed.
Figure 15 shows the measured result of the falling trajectory from the large bell during the scheduled shutdown. If the large bell stroke is decreased to $2 / 3$, the raw material comes to the interior side of furnace at the stock line level shown by the broken line in the figure, since the raw material is discharged from the position higher than the normal one. Therefore, raw materials are charged closer to the center of furnace if the stroke is $2 / 3$ of the case that the stroke is full at 0 point where the MA is not used. At 1 and 2 points with $2 / 3$ stroke, the main stream of raw materials is directed toward furnace periphery in comparison with the case that the stroke is full which corresponds to the MA. The effect to the falling position in the radial direction of furnace is considered to be less at 3 and 4 points since the MA is of the stone box type.

Based on these findings, the bell stroke control has been undergone in the order of $\mathrm{C}_{1} \mathrm{O}_{3} \rightarrow \mathrm{C}_{1} \mathrm{O}_{3}{ }^{2 / 3} \rightarrow$ $\mathrm{C}_{1} \mathrm{O}_{4} \rightarrow \mathrm{C}_{1} \mathrm{O}_{4}{ }^{2 / 3}$ from the above-mentioned viewpoint of the peripheral particle size segregation to strengthen mainly the peripheral gas flow, and the position has been changed to $\mathrm{C}_{1} \mathrm{O}_{3} \rightarrow \mathrm{C}_{1}{ }^{2 / 3} \mathrm{O}_{3} \rightarrow \mathrm{C}_{0}{ }^{2 / 3} \mathrm{O}_{3} \rightarrow \mathrm{C}_{0} \mathrm{O}_{3}$ to control by the coke falling position. The stroke speed has been slowed down according to the schedule of ore and coke charging for the purpose of distributing the coarse particle so that the permeability is not affected in the central region, for preventing excess suppression of the central gas flow when the peripheral gas flow is strengthened.

\section{Operation Results}

1. Correspondence between Particle Size/Layer Thickness Distribution and Sensor in Furnace Radial Direction

Figure 16 shows the comparison of gas distribution indexes during the typical MA pattern operation. Figure 16(a) shows the fixed probe temperature after ore charging $T_{\text {center }}$, and the difference between the fixed probe temperature after coke charging and ore charging $\Delta T_{\text {coke-ore }} / T G T$, and, $\Delta T_{C L} / T G T$. In this figure, $T G T$ means the top gas temperature. The $\Delta T_{C L} / T G T$ increases in $\mathrm{C}_{0} \mathrm{O}_{3}$ charging in which coke is charged toward the furnace wall side in comparison with $\mathrm{C}_{5} \mathrm{O}_{1}$ and $\mathrm{C}_{3} \mathrm{O}_{1}$ charging in which coke is charged toward the furnace central part. Further, the $\Delta T_{\text {coke-ore }} / T G T$ has decreased after the bell stroke and speed controlling.

The increase in $\Delta T_{C L}$ in the case of $\mathrm{C}_{0} \mathrm{O}_{3}$ charging in comparison with $\mathrm{C}_{5} \mathrm{O}_{1}$ and $\mathrm{C}_{3} \mathrm{O}_{1}$ charging, indicates the increase in $L o / L c$ peak near the central region as shown in Fig. 11 (a), and the decrease in $\Delta T_{\text {coke-ore }}$ $T G T$ indicates the decrease in $L o / L c$ of the central region.

On the other hand, Fig. 16(b) shows the comparison between the stave temperature index, $\Delta \mathcal{T}_{\text {wall }}$, $\mathrm{N}_{\text {wall }} / \mathrm{N}_{\text {center }}\left(\left(\eta_{\mathrm{co}}^{\mathbb{w}} \times 18-3\right) /\left(\eta_{\mathrm{co}}^{\mathrm{c}} \times 18-3\right)\right)$, and $L o / L c^{12)}$ at periphery, which indicate the gas index at the furnace wall. In comparison with the time of standard charging $\mathrm{C}_{0} \mathrm{O}_{3}$, the bell stroke and speed adjustments have brought about favourable results of the increase in $\Delta T_{\text {wall }}$, namely the decrease in the thermal flow ratio, and the increase in $\mathrm{N}_{\text {wall }} / \mathrm{N}_{\text {center }}$, namely the increase 
Fig. 15.

Falling trajectory from large bell measured at scheduled shut down of Chiba No. 5 Blast Furnace.
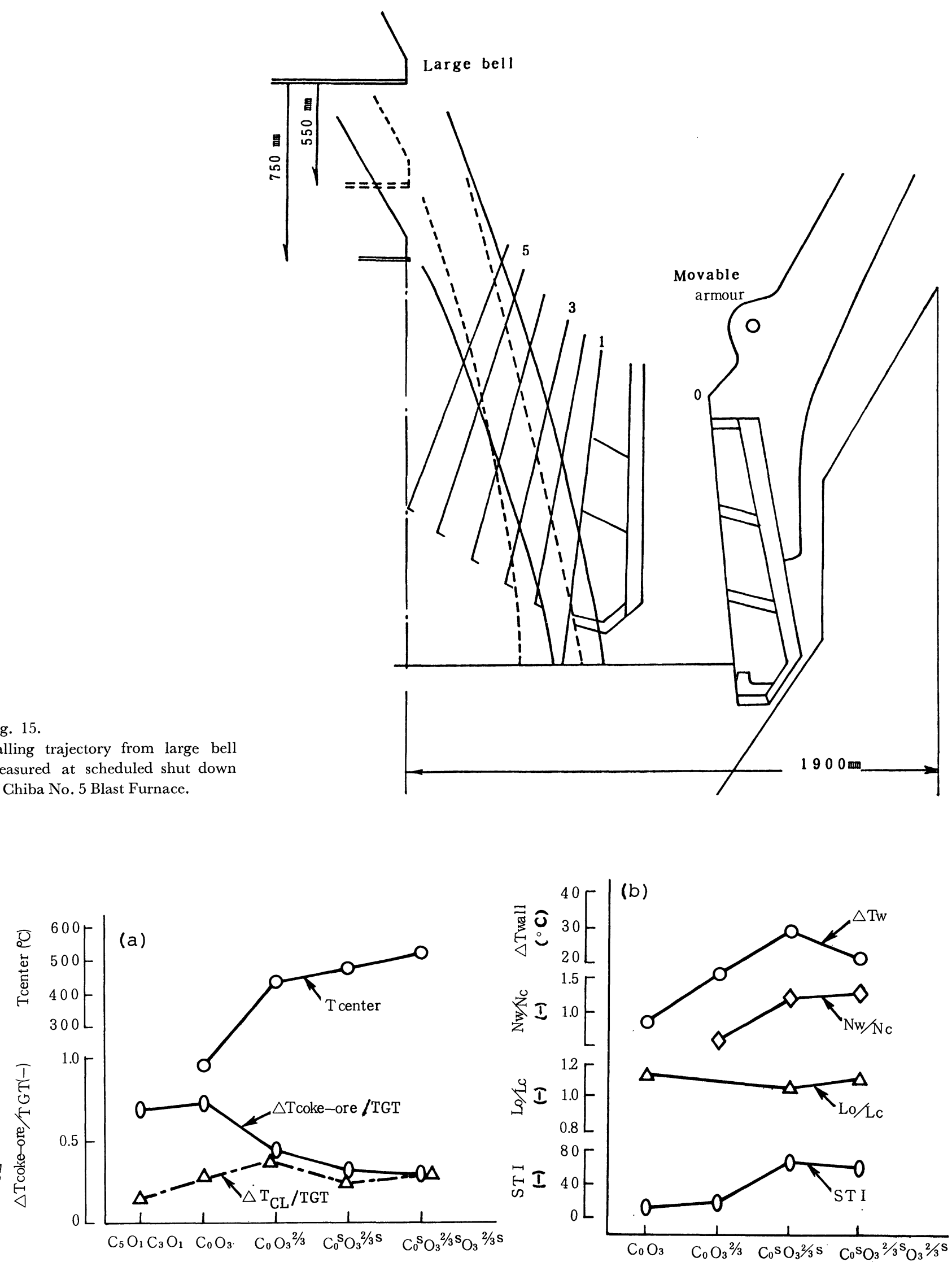

$\Delta T_{C L} / T G T:$ Central gas temperatureintermediate gas temperature

$T_{\text {center }}$ : Central gas temperature measured by fixed probe
$\Delta T_{\text {coke-ore }} / T G T:$ Difference of central gas temperature between after coke charging and after ore charging

2/3: Bell stroke is $2 / 3$. $s:$ Bell stroke speed is slow.

$\Delta T_{W}$ : Peripheral gas temperature-intermediate gas temperature

$\mathrm{N}_{i}: \quad\left(\eta_{\mathrm{CO}} \times 18-3\right)$ at $i$ point

STI: Stave temperature index

Fig. 16. Trends of typical operational indeces indicated the central gas flow and peripheral gas flow. 
Table 2. Conceptual flow for burden distribution.

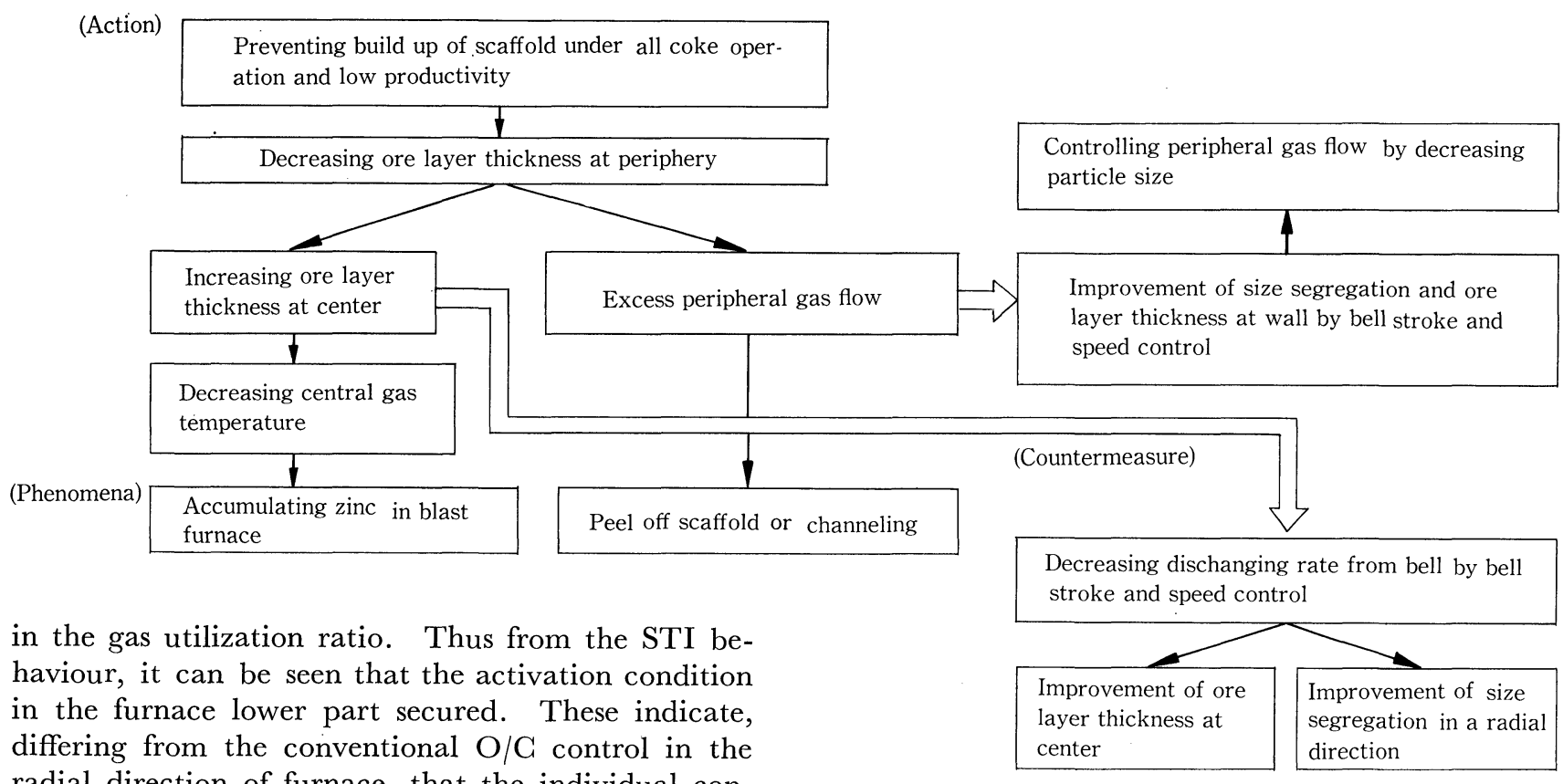
radial direction of furnace, that the individual control of the particle size and layer thickness is important.

The bell stroke and speed control technique of the all coke operation under the reduction of productivity to $1.50 \mathrm{t} / \mathrm{m}^{3} \cdot d$ or less has the meaning shown in the conceptual flow in Table 2. Namely, the layer thickness at the periphery is lowered to suppress the formation of scaffold. At this time, it is necessary to prevent the gas flow from flattening due to the increase in ore layer thickness at the central region.

The decrease in the charging rate from the large bell can prevent the gas flow from flattening by the decrease in flow-in energy of ore in the central region and the improvement in permeability due to the segregation of coarse particles. On the other hand, the decrease in layer thickness at the periphery will cause the channeling. To prevent this, it is important to suppress the peripheral gas flow by increasing the resistance for permeability using fine-particle ore of excellent reducibility, without increasing the $\mathrm{O} / \mathrm{C}$. The improvement in the particle size segregation by the bell stroke and speed control is a useful method for particle size control not only in the central region but also in the periphery region.

\section{Improvement of Operation}

Figure 17(a) shows an example in which the increase in the peripheral gas flow has been attained by setting the armour location at point 3 at the time of ore charging and by setting the large bell stroke at 2/3, and Fig. 17(b) shows an example in which the increase in the peripheral gas flow has been attained by setting the large bell stroke to $2 / 3$ at coke point 1 .

Figure 17(c) shows an example in which the central gas flow has been strengthened by changing the large bell speed from 12 to $24 \mathrm{~s} / 750 \mathrm{~mm}$ for coke and from 8 to $16 \mathrm{~s} / 550 \mathrm{~mm}$ for ore. By adjusting the bell stroke and speed as described above, it has become possible to control the central gas flow which conven-
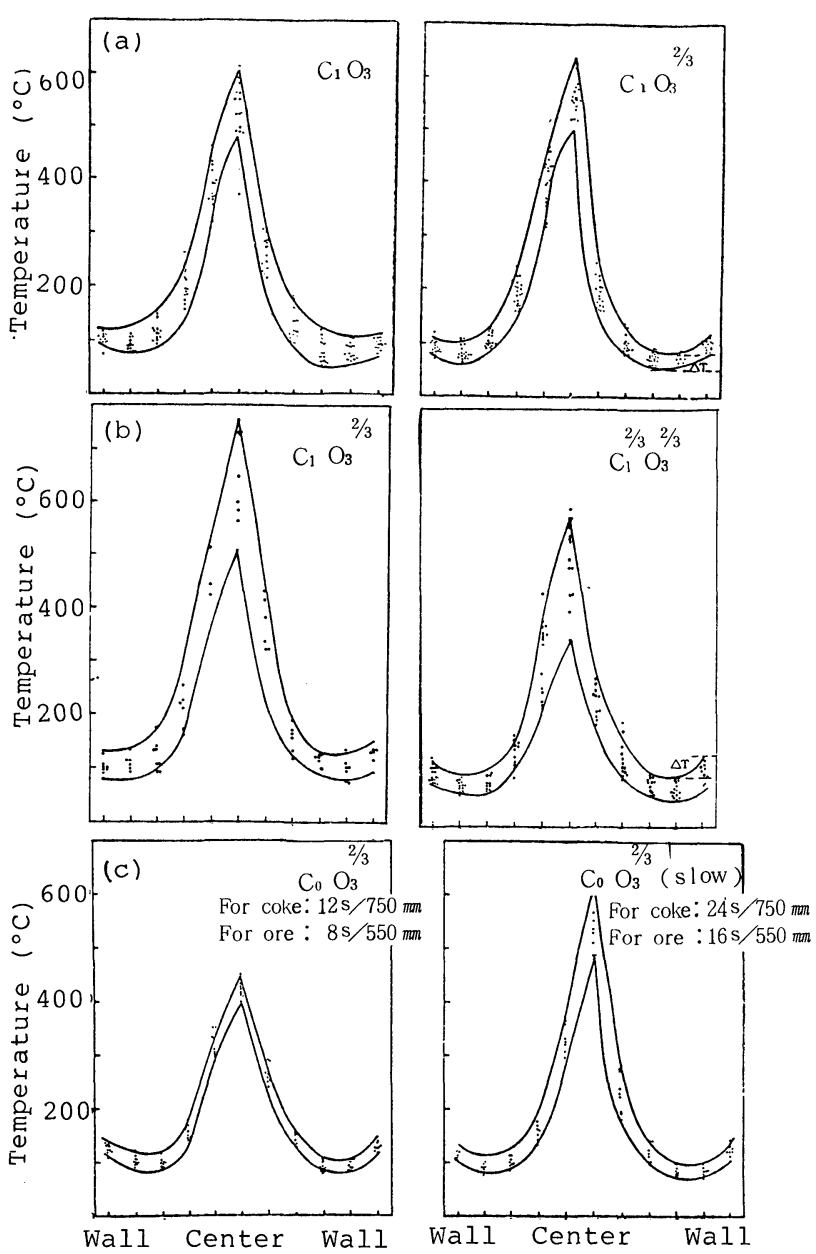

(a) $\mathrm{C}_{1} \mathrm{O}_{3} \rightarrow \mathrm{C}_{1} \mathrm{O}_{3}^{2 / 3}$

(b) $\mathrm{C}_{1} \mathrm{O}_{3}^{2 / 3} \rightarrow \mathrm{C}_{1}{ }^{2 / 3} \mathrm{O}_{3}{ }^{2 / 3}$

(c) $\mathrm{C}_{0} \mathrm{O}_{3}^{2 / 3} \rightarrow \mathrm{C}_{0} \mathrm{O}_{3}^{2 / 3}$ (slow)

Fig. 17. Change of the gas temperature distribution by bell stroke control. 
Table 3. Comparison of typical blast furnance operation.

\begin{tabular}{l|ccccc}
\hline & Jan., 1981 & Oct., 1981 & Dec., 1981 & May, 1982 & Sep., 1982 \\
\hline Zn percent in dust (\%) & 0.07 & 0.22 & 0.11 & 0.36 & 0.23 \\
Stave temperature index $(-)$ & 43.4 & 15.7 & 9.6 & 13.3 & 22.6 \\
Large and small slip frequency (times/month) & 15,36 & 115,95 & 102,72 & 32,15 & 14,15 \\
Permeability ( - ) & 0.69 & 0.75 & 0.71 & 0.67 & 0.66 \\
Minimum of hot metal temperature $\left({ }^{\circ} \mathrm{C}\right)$ & 1428 & 1403 & 1463 & 1465 & 1473 \\
Typical MA position & $\mathrm{C}_{1} \mathrm{O}_{0}$ & $\mathrm{C}_{4} \mathrm{O}_{1}$ & $\mathrm{C}_{1} \mathrm{O}_{3}$ & $\mathrm{C}_{0} \mathrm{O}_{3}^{2 / 3}$ & $\mathrm{C}_{0} \mathrm{O}_{3}^{2 / 3}($ slow) \\
\hline
\end{tabular}

tionally has tended to be flat distribution and to secure a stabilized gas flow in the periphery region. Table 3 shows the comparison of typical operational results at Chiba No. 5 Blast Furnace. The bell stroke and speed changing technique has achieved a proper stave temperature index, and as a result, the acute drop of molten metal temperature has been eliminated and the slip frequency has been reduced, thereby contributing to stabilized the operation. ${ }^{14)}$

\section{Conclusions}

In Chiba No. 5 Blast Furnace equipped with the movable armour of Kawasaki type, the new distribution control method by the change of bell stroke and bell stroke speed has been established through two years operation after its blowing in. The information obtained and its contents are summarized below.

(1) The technical problem in MA is the flattening of gas distribution when the gas flow is of a peripheral flow. This flattening is due to the effects by the increase in the ore flow to the central part and by the flow of fine particles to the central part, since the discharging rate from the bell is high.

(2) To improve particle size segregation in the radial direction of furnace at the conventional bellarmour type blast furnace, the technique of changing the bell stroke and speed has been developed. The technique is aimed at decreasing the layer thickness and increasing the coarse particle segregation in the central part by slowing down the raw material discharging rate from the bell.

(3) The technique has made possible to strengthen the peripheral gas flow and the central gas flow simultaneously, and thus has greatly contributed to sta- bilizing the furnace condition and extension of the latitude of operation under the recent circumstances being forced to reduce the production.

\section{REFERENGES}

1) K. Okumura, T. Kawai, H. Marushima, H. Takahashi and J. Kurihara: Tetsu-to-Hagané, 66 (1980), 1956.

2) T. Haru and J. Kurihara: The 2nd ILAFA-Blast Furnace Congress, ILAFA, Rio de Janeiro, May, 1982 ; Steel Times, (1982), July, 369.

3) S. Kajikawa, R. Yamamoto, R. Nakajima, J. Kishimoto and T. Fukushima: Tetsu-to-Hagané, 68 (1982), 2361.

4) M. Yasuno, K. Tanaka, T. Kawai, M. Watanabe and J. Kurihara: Tetsu-to-Hagané, 67 (1981), S771.

5) K. Hayase and H. Takahashi: Kawasaki Steel Giho, 13 (1981), No. 4, 59.

6) S. Taguchi, T. Koitabashi, N. Tsuchiya and H. Takahashi: Tetsu-to-Hagané, 68 (1982), 2346.

7) S. Taguchi, H. Katayama, N. Tsuchiya, K. Okabe, K. Tanaka and K. Okumura: Stahl u. Eisen, 101 (1981), No. $18,43$.

8) J. Kurihara, S. Hashizume, H. Takahashi, K. Okumura, H. Marushima and T. Kawai: Tetsu-to-Hagané, 66 (1980), S103.

9) S. Sakurai: Tetsu-to-Hagané, 68 (1982), 2319.

10) Nippon Kokan K. K.: Ironmaking Comm., The Joint Research Society, ISIJ, (1980), Nos. 57-6 \& 19 (Private).

11) T. Isoyama, E. Chikamatsu, T. Saitoh, Y. Okuno, T. Imai and A. Suzawa: Tetsu-to-Hagané, 67 (1981), S83.

12) K. Okumura, T. Kawai, H. Marushima, H. Takahashi and J. Kurihara: Trans. ISIJ, 22 (1982), 244.

13) N. Inagaki, M. Baba, K. Asai, N. Kusakabe and T. Suehiro: Tetsu-to-Hagané, 69 (1983), 656.

14) T. Haru, M. Saino, M. Yasuno, K. Okumura, K. Kaneko, T. Sawada and Y. Konishi: Tetsu-to-Hagané, 69 (1983), S58. 